\title{
Water Absorption and Thickness Swelling of Oil Palm Empty Fruit Bunch (OPEFB) and Seaweed Composite for Soil Erosion Mitigation
}

Teh Wen Fang, ${ }^{1}$ Nurin Syahindah Syasya Nur Asyikin, ${ }^{1}$ Abdul Khalil H. P. Shawkataly, ${ }^{1}$ Mohamad Haafiz Mohamad Kassim ${ }^{1}$ and M. I. Syakirir,

${ }^{1}$ School of Industrial Technology, Universiti Sains Malaysia, 11800 USM Pulau Pinang, Malaysia

${ }^{2}$ Centre for Global Sustainability Studies (CGSS), Universiti Sains Malaysia, 11800 USM Pulau Pinang, Malaysia

*Corresponding author: misyakir@usm.my

Published online: 15 August 2017

To cite this article: Teh, W. F. et al. (2017). Water absorption and thickness swelling of oil palm empty fruit bunch (OPEFB) and seaweed composite for soil erosion mitigation. $J$. Phys. Sci., 28(2), 1-17, https://doi.org/10.21315/jps2017.28.2.1

To link to this article: https://doi.org/10.21315/jps2017.28.2.1

\begin{abstract}
Sedimentation in river triggered by soil erosion has an impact on the ecosystem services. Application of natural biomass on residual as biodegradable material has been of great attention due to its environmental friendliness. In this study, oil palm empty fruit bunch (OPEFB) and seaweed are applied as a composite to evaluate the water holding capacity and thickness swelling as soil stabiliser. The alkaline treatment is introduced to improve the surface bonding of fibres with binder. The dimensional stability test was conducted according to standard ASTM D 5229 to obtain average water absorption and thickness swelling. The average water absorption and thickness swelling for the nontreated composite are $297.07 \%( \pm 6.47)$ and $7.78 \%( \pm 3.34)$ respectively, while for the alkaline treated composite, it demonstrates lower water absorption $(222.60 \%$ ( \pm 4.38$))$ but higher thickness swelling 18.23\% ( \pm 4.23). This showed that both of the composites have high water content mainly due to dimensional stability. Scanning electron microscopy (SEM) micrographs display better interface adhesion between OPEFB fibre and seaweed after alkaline treatment compare to non-treated composite. Fibre breakage was observed for the non-treated composite, suggesting that it is incapable to withstand the tension created by water during the immersion.
\end{abstract}

Keywords: Oil palm empty fruit bunch (OPEFB), water absorption, dimensional stability, ecosystem service, soil stabiliser 


\section{INTRODUCTION}

Malaysia is the world's leading producer of palm oil having $50,000 \mathrm{~km}^{2}$ of oil palm plantations and 423 palm oil mills operating in the country. ${ }^{1}$ After producing the valuable products, a large amount of biomass is generated as waste including the trunks, fronds and empty fruit bunch (EFB). Oil palm empty fruit bunch (OPEFB) is unfavourable to handle due to its wet, bulky and voluminous properties. Similarly, seaweed is another abundant resource found in Malaysia, mainly in Sabah. Seaweed is known as a useful and low-cost material but it is only widely used in agriculture industry as it contains beneficial elements to plant and soil. Back in 1950s, seaweed was extracted to be used as fertilisers for plantations in order to boost the food production in Europe and North America.

In recent years, Malaysia has been encountering the issue of floods mainly due to runoff of water and erosion of soil into the river, causing the riverbed level to rise. OPEFB consists of several good characteristics which enables it to form a good composite with seaweed, which serves as a matrix bed to mitigate soil erosion issue. At the same time, seaweed is abundantly found locally as an attractive material in recent studies due to its several good characteristics, which are hydrophilic, biodegradable, non-toxin and safe to environment. An exploratory study has employed seaweed to enhance the mechanical properties and water absorption of the composite. ${ }^{2}$ In this way, the waste of OPEFB can be reduced and reused to solve the soil erosion issue, whilst seaweed can be used to add nutrient value into the soil. OPEFB fibre and seaweed are both promising materials having good potential in reducing soil erosion.

However, when using both materials to make a composite for water absorption purpose, the mechanical properties and compatibility are both critical elements to be defined. The formation of the interface in the layers of composite leads to the compatibility of OPEFB fibre. According to Alawar et al., incompatibility of composite often occurs as an issue when using natural fibre. ${ }^{3}$ Chemical treatment is a trusted method to modify the surface of natural fibres and improve the strength of the interfacial bond. Thus, the compatibility of the composite is a concern while making sure the composite is able to exhibit desirable characteristic, which is high water absorption. The desirable characteristics include high content of cellulose, high moisture absorption, wide availability, renewable, low density, lower energy requirement, biodegradable and cost effective. ${ }^{4}$

Although OPEFB fibres are naturally strong in mechanical properties such as tensile strength and flexural properties, the uptake of water by the composite causes swelling which will lead to changes in the dimensional stability. ${ }^{5}$ This particular 
reason turns the use of natural fibre as reinforced composites in polymers into a less ideal choice. Yet, the susceptibility of water in OPEFB fibre is one of the good characteristics contributing to the composite in this study.

The interfacial bonding and adhesion of the composite play important roles to provide good mechanical support. Upon the absorption of water, the mechanical properties of the fibre turn weaker as well. ${ }^{6}$ Alkaline treatment is one of the ways to improve the surface morphology and mechanical properties of the treated fibres. This treatment caused the removal of the hemicelluloses, wax, oils and lignin covering at the surface of fibre. The optimum treatment contributes to result mentioned above is under the treatment condition of $1 \%$ sodium hydroxide $(\mathrm{NaOH})$ for $1 \mathrm{~h}$ at $100^{\circ} \mathrm{C} .{ }^{4}$ According to Joseph et al., a better interfacial bonding in the application of alkaline treatment is produced. ${ }^{7}$ The removal of hemicelluloses and the lignin redistribution has increased the fibre porosity at the same time. Thus, the surface modification on OPEFB can be used to decrease the hydrophilic ability of material due to chemical and physical modification. Therefore, the main objective of this study is to investigate the physical and morphological properties (water absorption and thickness swelling) of alkaline treated and non-treated OPEFB fibre and seaweed composite.

\section{EXPERIMENTAL}

\subsection{Materials}

Seaweed sample is bought from Green Leaf Synergy (Sabah, Malaysia), while the OPF is obtained from United Oil Palm Industries (Nibong Tebal, Pulau Pinang, Malaysia). The physical and chemical properties of OPEFB fibre is as summarised in Table 1, meanwhile the minor content of seaweed fibre is presented in Table 2.

Table 1: Physical and chemical properties of OPEFB fibre. ${ }^{8}$

\begin{tabular}{ll}
\hline Property & Values \\
\hline Chemical property $(\%)$ & \\
Lignin & 19 \\
Cellulose & 65 \\
Ash & 2 \\
Physical property & \\
Density $(\mathrm{g} / \mathrm{cc})$ & 1.4 \\
Diameter $(\mu \mathrm{m})$ & $150-500$ \\
\hline
\end{tabular}


Table 2: Minor content of seaweed fibres. ${ }^{9}$

\begin{tabular}{llll}
\hline Ingredients & Content $(\mathrm{wt} \%)$ & Ingredients & Content $(\mathrm{mg} / \mathrm{kg} \mathrm{DM})$ \\
\hline Nitrogen & 0.05 & Aqua regia zinc & 142 \\
Phosphate & 0.08 & Aqua regia copper & 9.38 \\
Potash & 0.20 & Aqua regia iron & 476 \\
Aqua regia calcium & 0.56 & Aqua regia manganese & 42.13 \\
Aqua regia magnesium & 1.04 & Aqua regia sulphur & 21900 \\
Aqua regia sodium & 7.54 & Boron & 363 \\
\hline
\end{tabular}

\subsection{Composite Preparation}

OPEFB is dismantled into single fibres and cleaned with distilled water to get rid of oily matters. The fibres are air dried for $24 \mathrm{~h}$ before transferred into force-air convention oven for another $24 \mathrm{~h}$ at $80^{\circ} \mathrm{C}$. The fibres are ground into desired length (50-100 mm) by using grinder (Riken, RAB-15T1S3) from Riken Electric Co., Taiwan.

The seaweed is washed with distilled water to clear off any impurities before dried in oven at temperature of $40^{\circ} \mathrm{C}$ for 4 days. The sample is then kept in an airtight bottle prior to the composite preparation.

For alkaline treatment, the fibres are immersed in $1 \% \mathrm{NaOH}$ for $1 \mathrm{~h}$ at $100^{\circ} \mathrm{C}$ with continuous heating. ${ }^{3}$ The fibres are cooled to room temperature and rinsed with distilled water, and dried in a vacuum oven at $60^{\circ} \mathrm{C}$ for $24 \mathrm{~h}$.

Next, $25 \mathrm{~g}$ of seaweed is heated at $100^{\circ} \mathrm{C}$ before mixed with $40 \mathrm{~g}$ of OPEFB fibre. The mixture then is poured into a mold dimension of $120 \mathrm{~mm} \times 120 \mathrm{~mm} \times 1.5 \mathrm{~mm}$. After that, the mold is placed on the lower movable platen of the hydraulic press for 1 day in 1000 psi to compact the structure of the composite. Five replications are prepared for both treated and non-treated composites.

\subsection{Water Absorption and Thickness Swelling Test}

Water absorption and thickness swelling are assessed following ASTM D 5229 standard. Specimens of $60 \mathrm{~mm} \times 60 \mathrm{~mm} \times 1.5 \mathrm{~mm}$ are prepared from the composites. The samples are stored in desiccator containing silica gel to keep the sample dry and to prevent the growth of fungus on the sample. Before testing, the weight and thickness of each sample are measured. For water absorption test, the samples of each type of composite (treated and untreated) are immersed in $200 \mathrm{ml}$ 
of distilled water at room temperature. The specimens are taken out and dried with an absorbent lint-free towel or tissue papers to remove excess water on the surface before immediately weighed by using digital balance. $2,5,6,10,11$

The thickness swelling measurements of the samples are then measured using a dial callipers (Mitutoyo, 505-641) before and after the water absorption test. The specimens are then placed back into the water instantly. This procedure is repeated continuously for every $5 \mathrm{~min}$ for five replications until the effective moisture equilibrium is reached, which means the constant weight of specimens is obtained. According to ASTM D 5229 standard method, the water absorption and thickness swelling are calculated by using Equations 1 and 2 respectively:

Water absorption $=\frac{W_{i}-W_{o}}{W_{o}}$

Where: $W_{i}=$ The weight of specimens after immersion, $\mathrm{g}$ $W_{o}=$ The weight of specimens before immersion, $\mathrm{g}$

Thickness swelling $=\frac{T_{1}-T_{0}}{T_{0}} \times 100 \%$

Where: $T_{1}=$ The thickness of specimens after immersion in distilled water, $\mathrm{mm}$

$T_{0}=$ The thickness of specimens before immersion, $\mathrm{mm}$

\subsection{Morphology Analysis}

The morphology of composites is analysed using ZEISS, 51- ADD0048 scanning electron microscope (SEM) at $15 \mathrm{kV}$. The samples are coated by gold-sputtering before the SEM analysis is performed. The sample is mounted on aluminium holders using double-sided electrically conducting carbon adhesive tabs prior to analysis.

\section{RESULTS AND DISCUSSION}

Many researchers conducted this test on nature fibre and polymer matrix to evaluate water absorption behaviour. ${ }^{12}$ In most studies, the weight gain or weight loss of material composite are the interested parameter to manifest percentage of moisture content. ${ }^{13}$

The average water absorption of the composite is calculated based on Equation 1 in order to determine the amount of water absorbed under a certain condition. 
The average values of water absorption and thickness swelling for both non-treated and treated composites are presented in Table 3 and Table 4.

Table 3: Average water absorption for treated and non-treated composite for $60 \mathrm{~min}$.

\begin{tabular}{|c|c|c|c|c|}
\hline \multirow{3}{*}{$\begin{array}{c}\text { Time interval (min) } \\
5\end{array}$} & \multirow{2}{*}{\multicolumn{2}{|c|}{$\begin{array}{l}\text { Non-treated composite } \\
\text { Moisture content }(\%)\end{array}$}} & \multirow{2}{*}{\multicolumn{2}{|c|}{$\begin{array}{c}\text { Treated composite } \\
\text { Moisture content }(\%)\end{array}$}} \\
\hline & & & & \\
\hline & 225.1397 & \pm 9.9874 & 147.4270 & \pm 19.9371 \\
\hline 10 & 248.7898 & \pm 18.8300 & 181.8549 & \pm 11.5356 \\
\hline 15 & 269.8533 & \pm 10.0085 & 205.8671 & \pm 10.7276 \\
\hline 20 & 295.2580 & \pm 7.2932 & 215.8906 & \pm 11.8445 \\
\hline 25 & 299.7944 & \pm 3.7422 & 223.2578 & \pm 6.1238 \\
\hline 30 & 307.9629 & \pm 6.3455 & 233.3803 & \pm 6.1619 \\
\hline 35 & 317.9340 & \pm 7.1146 & 236.0401 & \pm 12.9619 \\
\hline 40 & 334.8347 & \pm 7.3459 & 240.0804 & \pm 12.4832 \\
\hline 45 & 333.5239 & \pm 16.6141 & 238.1933 & \pm 18.4036 \\
\hline 50 & 337.6278 & \pm 19.1759 & 248.9254 & \pm 19.0647 \\
\hline 55 & - & - & 250.7251 & \pm 16.4693 \\
\hline 60 & - & - & 249.5946 & \pm 16.6081 \\
\hline Average & 297.0718 & \pm 6.4744 & 222.6030 & \pm 4.3754 \\
\hline
\end{tabular}

Data are means \pm stdev $(N=20)$.

Table 4: Average thickness swelling for treated and non-treated composite for $60 \mathrm{~min}$.

\begin{tabular}{|c|c|c|c|c|}
\hline \multirow{3}{*}{$\begin{array}{c}\text { Time interval (min) } \\
5\end{array}$} & \multirow{2}{*}{\multicolumn{2}{|c|}{$\begin{array}{l}\text { Non-treated composite } \\
\text { Thickness swelling (\%) }\end{array}$}} & \multirow{2}{*}{\multicolumn{2}{|c|}{$\begin{array}{c}\text { Treated composite } \\
\text { Thickness swelling (\%) }\end{array}$}} \\
\hline & & & & \\
\hline & 10.9963 & \pm 6.8863 & 17.3006 & \pm 7.3583 \\
\hline 10 & 10.0984 & \pm 5.2371 & 21.2175 & \pm 8.1247 \\
\hline 15 & 8.8289 & \pm 4.3896 & 20.4347 & \pm 7.8849 \\
\hline 20 & 8.5796 & \pm 4.0229 & 17.2030 & \pm 4.0076 \\
\hline 25 & 8.5165 & \pm 4.6325 & 18.3424 & \pm 6.4053 \\
\hline 30 & 8.3779 & \pm 3.6412 & 16.7832 & \pm 4.1366 \\
\hline 35 & 8.3947 & \pm 2.8334 & 18.1533 & \pm 4.7250 \\
\hline 40 & 6.8982 & \pm 5.2196 & 19.1846 & \pm 4.0573 \\
\hline 45 & 4.6381 & \pm 6.2965 & 18.1117 & \pm 2.9390 \\
\hline
\end{tabular}


Table 4: (continued)

\begin{tabular}{ccccc}
\hline \multirow{2}{*}{ Time interval $(\mathrm{min})$} & \multicolumn{2}{c}{ Non-treated composite } & \multicolumn{2}{c}{ Treated composite } \\
\cline { 2 - 5 } & \multicolumn{2}{c}{ Thickness swelling $(\%)$} & \multicolumn{2}{c}{ Thickness swelling (\%) } \\
\hline 50 & 2.5395 & \pm 5.5501 & 18.7974 & \pm 4.1061 \\
55 & - & - & 18.4448 & \pm 3.1635 \\
60 & - & - & 14.7994 & \pm 4.4735 \\
Average & 7.7868 & \pm 3.3408 & 18.2310 & \pm 4.2349 \\
\hline
\end{tabular}

Data are means \pm stdev $(N=20)$.

\subsection{Water Absorption of Composites}

In water absorption test (Figure 1), the results show that there is a huge increment of water absorption for five of the replicated samples compared to the initial state after soaking only $5 \mathrm{~min}$ in the water. In the first $5 \mathrm{~min}$, the composites gain at least three times of its initial dry weight and after that increase gradually for the rest of the time intervals. According to Jawaid et al., cellulose is one of the components in the OPEFB fibres showing hydrophilic characteristic that causes water uptake and capillary action during the water absorption test. ${ }^{4}$ The capillary action occurs in the tiny spaces within the fibre composite allows the water to transfer naturally resulting in an increase of moisture content. ${ }^{14}$ Since OPEFB fibre has high percentage of cellulose as shown in Table 1, the large intake of water by both treated and non-treated composite can be clearly explained.

Based on the bar graph plotted in Figure 1, the immersion time of non-treated composite lasts for $50 \mathrm{~min}$, while the treated composite lasts for $60 \mathrm{~min}$ before the composites start to detach. However, at $50 \mathrm{~min}$, the weight gain of the composites becomes lesser as the fibre had nearly approached moisture equilibrium, causing only small changes in percentage of water absorption. According to Pandian et al., the water absorption behaviour is highly dependent on the voids available in the composite itself thus, the water will first fill up the empty voids rapidly through capillary action until the voids turn limited. ${ }^{10}$ The non-treated composite samples start to detach from 50 min onwards due to the dimensionally unstable structure, causing the difficulties in taking measurement of the composite. The void content in the composite that allows water absorption can affect the degradation and its interfacial bond. ${ }^{9}$ Besides that, the solubility nature of seaweed also is another factor that causes the detachment of this composite in water. Sodium alginate is a natural hydrophilic polysaccharide presents in seaweed which performs good gelling properties as binder. ${ }^{15}$ Alginate tends to be relatively soluble in water because it contains high number of hydroxyl group. ${ }^{15}$ This contributes to composite 
degradation in this study while seaweed started to dissolve in water as displayed in Figure 2.

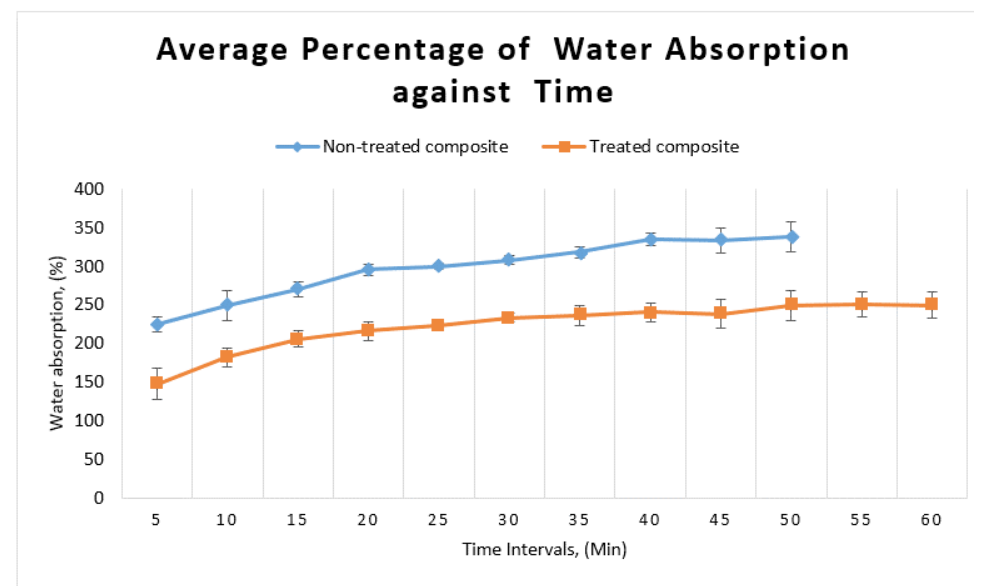

Figure 1: Average water absorption for both non-treated and treated composite in 60 min.

The average water absorption achieved for non-treated composite is $297.07 \%$ $( \pm 6.47)$ while for treated composite has lower average water absorption than the nontreated composite, which is $222.60 \%( \pm 4.38)$. Based on Figure 1, the overall trend of average water absorption for non-treated composite samples grow substantially for every 5 min until 40 min ranging from $225.14 \%( \pm 9.99)$ to $337.63 \%$ $( \pm 19.18)$; whereas the treated composite grow moderately for every 5 min until 40 min ranging from the lowest $147.43 \%( \pm 19.94)$ to the highest $250.73 \%( \pm 16.47)$. Valadez-Gonzalez et al. mentioned that alkaline treatment helps to remove and dissolve the hemicelluloses, waxes and lignin partially from the external surface of fibre. ${ }^{16}$ This provides a rougher surface and higher porosity of OPEFB fibre, thereby leading to difficulties in water retention within the composite. ${ }^{14,17,18}$ The water can be easily seeped through the pores on the fibre surface instead of retaining in the composite. Hence, the declination of water absorption performance in alkaline treated composite than the non-treated composite can be clearly explained. 


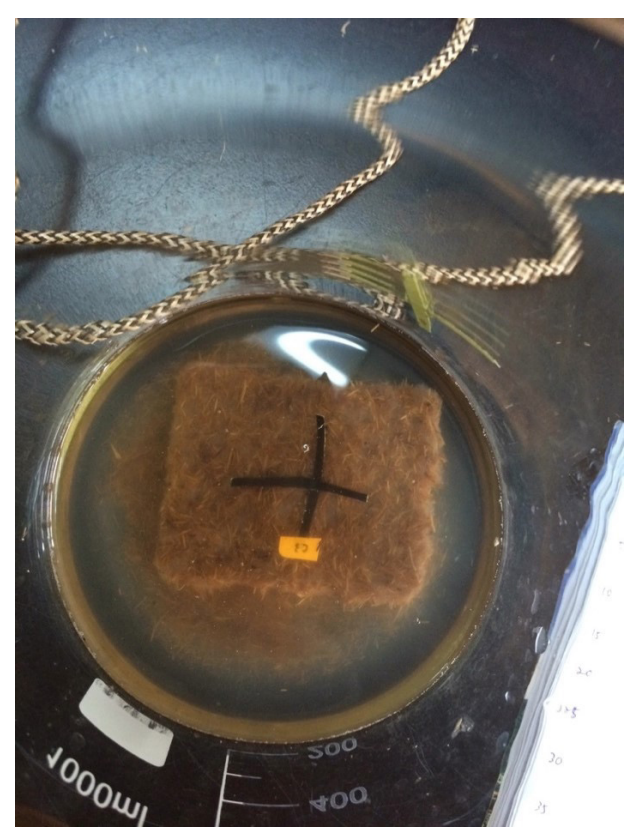

Figure 2: Seaweed detached gradually from composite at $50 \mathrm{~min}$ during water immersion test.

\subsection{Thickness Swelling of Composites}

Dimensional stability is the ability of material to maintain its original dimensions under the exposure of temperature and humidity changes. Thickness swelling is closely related to the dimensional stability of a composite. ${ }^{4}$ When the composite is exposed to different humidity and temperature, stress is induced in between the layers of composite resulting in degradation of fiber matrix interface. ${ }^{19}$ The uptake of the water changed the thickness and affects the dimension of the composite. The thickness swelling test is supposed to be carried out continuously until a constant weight is obtained, in which the effective moisture equilibrium is achieved. However, the measurement of thickness swelling in this study was only able to carry out until $50 \mathrm{~min}$ due to the detachment of composite.

In Figure 3, it is observed that most of the thickness of the replicated samples expands throughout the period time, but the thickness swelling percentage increased at the beginning and remain fluctuated until the end. The overall thickness swelling obtained from dimensional stability test is $18.23 \%( \pm 4.23)$. The highest average thickness swelling achieved by treated composite is $21.21 \%( \pm 8.12)$ at $10 \mathrm{~min}$ and the lowest swelling value is $14.80 \%( \pm 4.47)$ at $60 \mathrm{~min}$. However, for non- 
treated composite, the overall thickness swelling is $7.79 \%$ ( \pm 3.34$)$. Initially, the composite had the average thickness swelling of $11.00 \%( \pm 6.89)$ but obtained $2.54 \%( \pm 5.55)$ at $50 \mathrm{~min}$ due to composite degradation. It is obvious to see that the thickness swelling increased lesser and fluctuate after $30 \mathrm{~min}$ of experiment. Exposure of the composite to water absorption in a certain period of time affect the strength and toughness of the composite. The fibre swelling resulting in formation of weak bond between the fibres and the binder, and thus micro-cracks can happen to cause a brittle matrix thus, explains the decreasing value appeared in thickness swelling in both samples. ${ }^{20}$

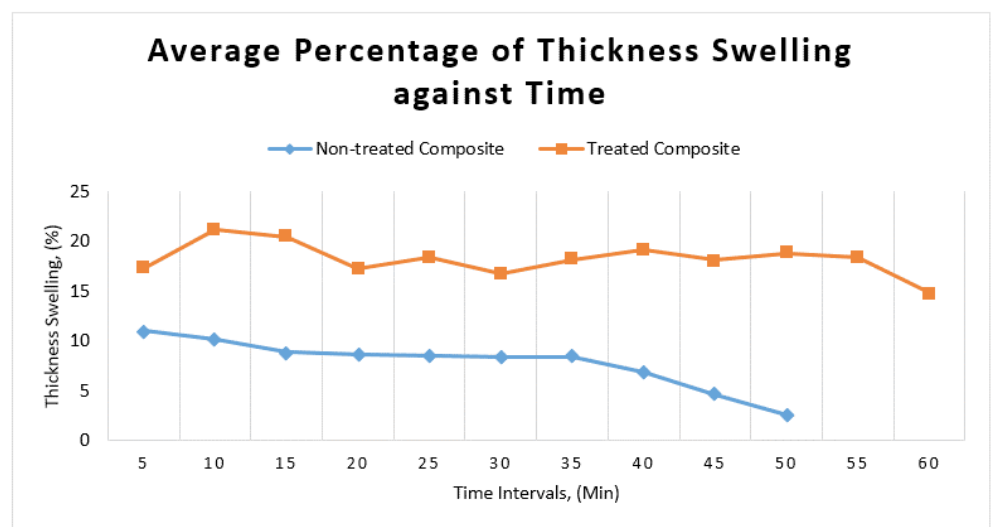

Figure 3: Average thickness swelling for both non-treated and treated composite over the time period.

In addition, the effect of water absorption is not only on the thickness, yet it expands the whole dimensional area of the composite samples. ${ }^{21}$ The trend of the thickness increment is less obvious compared to the weight increment. This is because the water molecules within the cellulose voids are capable to destroy the rigidity of the cellulose structure and causing softening effect. Thus, the increment of the thickness is not obvious as the fibre dimensions are changed easily. ${ }^{22}$ This clearly proved that the composite expands in both direction, vertically and horizontally when immersed in water.

In contrast, the alkaline treated composite achieves higher thickness swelling compare to non-treated composite. It is shown from Figure 3 that the immersion time for all of the three samples has prolonged until $1 \mathrm{~h}$ and not to mention, the thickness swelling of treated composite are averagely higher than non-treated composite starting from the beginning. This indicates that the treated composites are able to withstand a longer period in water before the seaweed starts to dissolve in water compared to non-treated composite. This is because the treatment enhances 
the number of possible reaction site on the fibre surface and promotes better mechanical interlocking within the composite. ${ }^{16}$ Improvement of adhesion between fibres creates dimensionally stable composite before reaching the saturated state which micro-cracks appear. When the water molecules enter the cellulose network, the fibre is strong enough to support the swelling and provide a rigid increment of thickness swelling. Thus, the thickness swelling for a rigid composite is more measurable as disintegration of structure is avoided while taking measurement.

Hypothetically, the trend of thickness swelling has to be similar with water absorption, which is increasing with immersion time until certain extent. ${ }^{23}$ Yet, this study does not reflect the same result mainly due to the high hydrophilic characteristics shown in seaweed, resulting in unstable dimension as displayed in Figure 4.

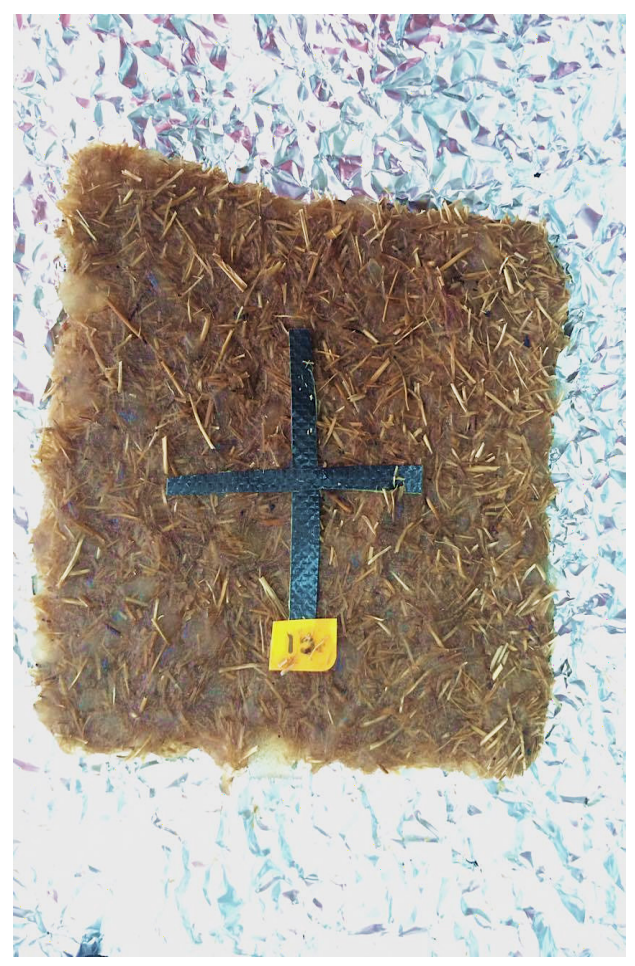

Figure 4: The deformity of shape was found upon water immersion test.

In this case, the expansion of dimension should be taken into account instead of only thickness swelling. However, with better surface modification upon treatment, the average thickness swelling for treated composite is higher than non-treated composites which are $18.23 \%( \pm 4.23)$ and $7.79 \%( \pm 3.34)$ respectively. 


\subsection{Surface Morphology}

\subsubsection{Pre-water absorption test}

The surface morphology of composite is examined under scanning electron microscope (SEM). Before the immersion of water, smooth surface plenty of pores on the cylindrical shape fibres without any chemical treatment is observed as in Figure 5. Since there is no surface modification towards the fibre, the cellulose material on the fibre surface is still able to absorb a remarkable amount of water. The water absorption ability gives another beneficial point in this study to facilitate the biodegradation process of composite during application as microorganisms in the soil depend on water for their growth. ${ }^{20}$

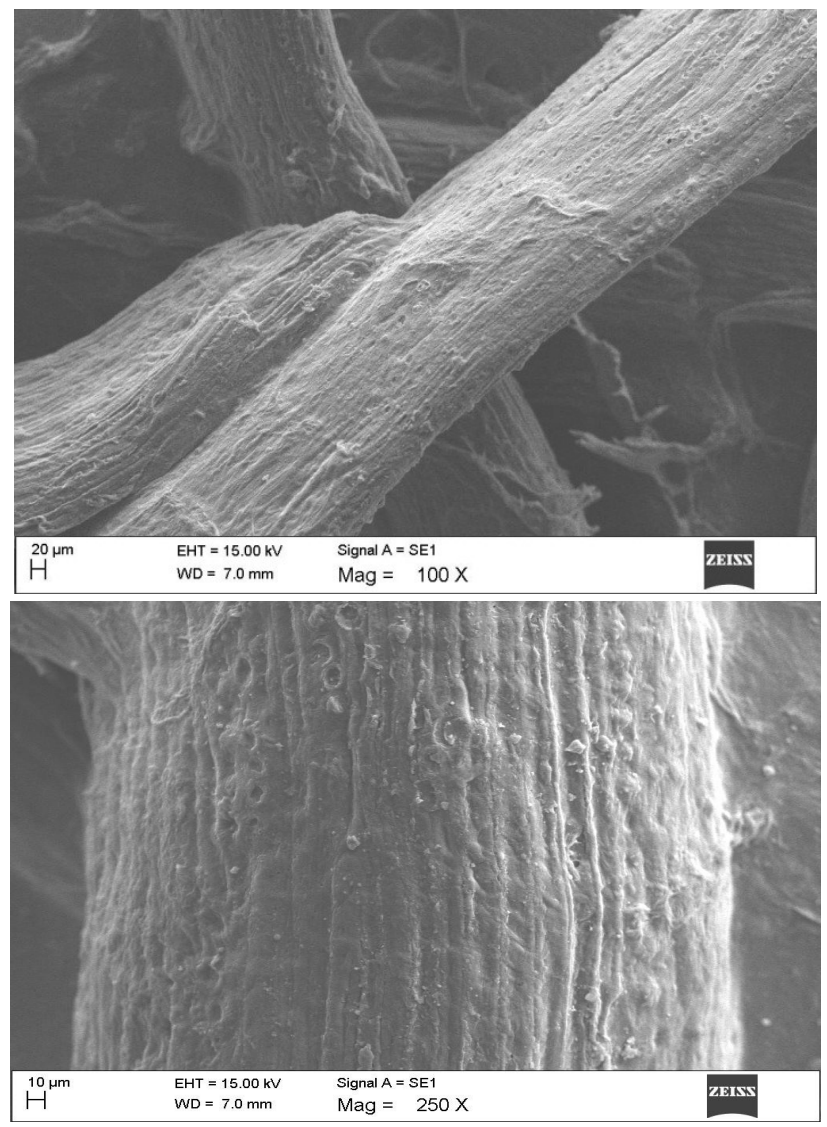

Figure 5: SEM micrographs of non-treated fibre under pre-immersion condition, (A) magnification at $100 \mathrm{X}$; (B) magnification at $250 \mathrm{X}$. 
In comparison, the alkaline treated OPEFB fibre in pre-immersion condition is as shown in Figure 6. The biggest difference is the number of pores on fibre surface increase to improve the interface adhesion between the OPEFB fibre and the seaweed binder. Although there is improvement in mechanical properties, the performance of water absorption is less ideal due to high porosity. However, the result obtained reflects that $1 \% \mathrm{NaOH}$ for $1 \mathrm{~h}$ at $100^{\circ} \mathrm{C}$ suggested by Alawar et al. is indeed an optimum treatment as there is improvement for surface morphology. ${ }^{3}$

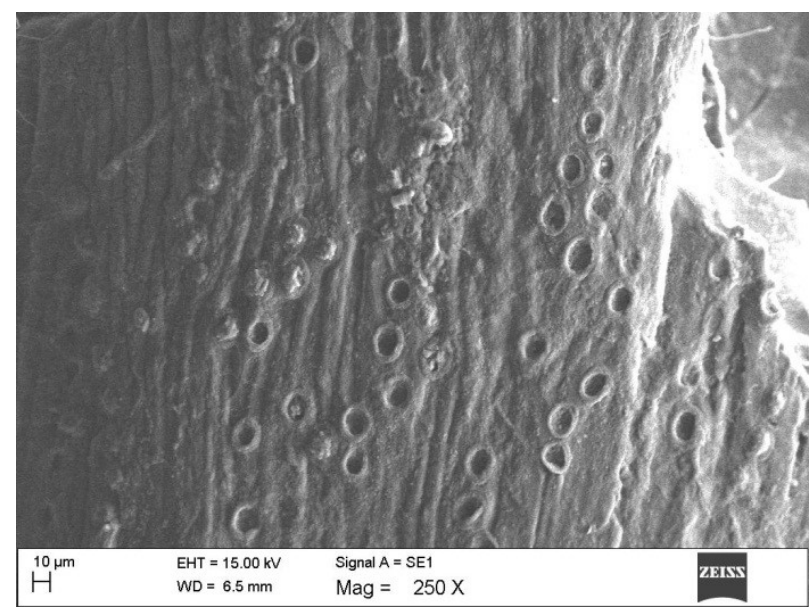

Figure 6: SEM micrographs of alkaline treated OPEFB fibre with increased number of pores under pre-immersion condition (magnification at 250X).

\subsubsection{Post water absorption test}

SEM micrographs of OPEFB fibre after water absorption test are examined for both non-treated and treated composites where the micrographs show some fragmented and broken fibres surrounded with binder of seaweed (Figure 7).

This indicates that fibre breakage and micro-crack happen at several parts of the fibre due to swelling. It is observed that the fibre breakage part for the non-treated composites appear more than the treated composite. This proves that the treated composite can withstand higher stress than non-treated composite. Muñoz and García-Manrique mentioned that the micro-cracks at interfacial region caused by fibre swelling are able to promote the diffusion of the water via the cracks. ${ }^{22}$ This could be another reason for non-treated composite demonstrating higher moisture content after water immersion. 

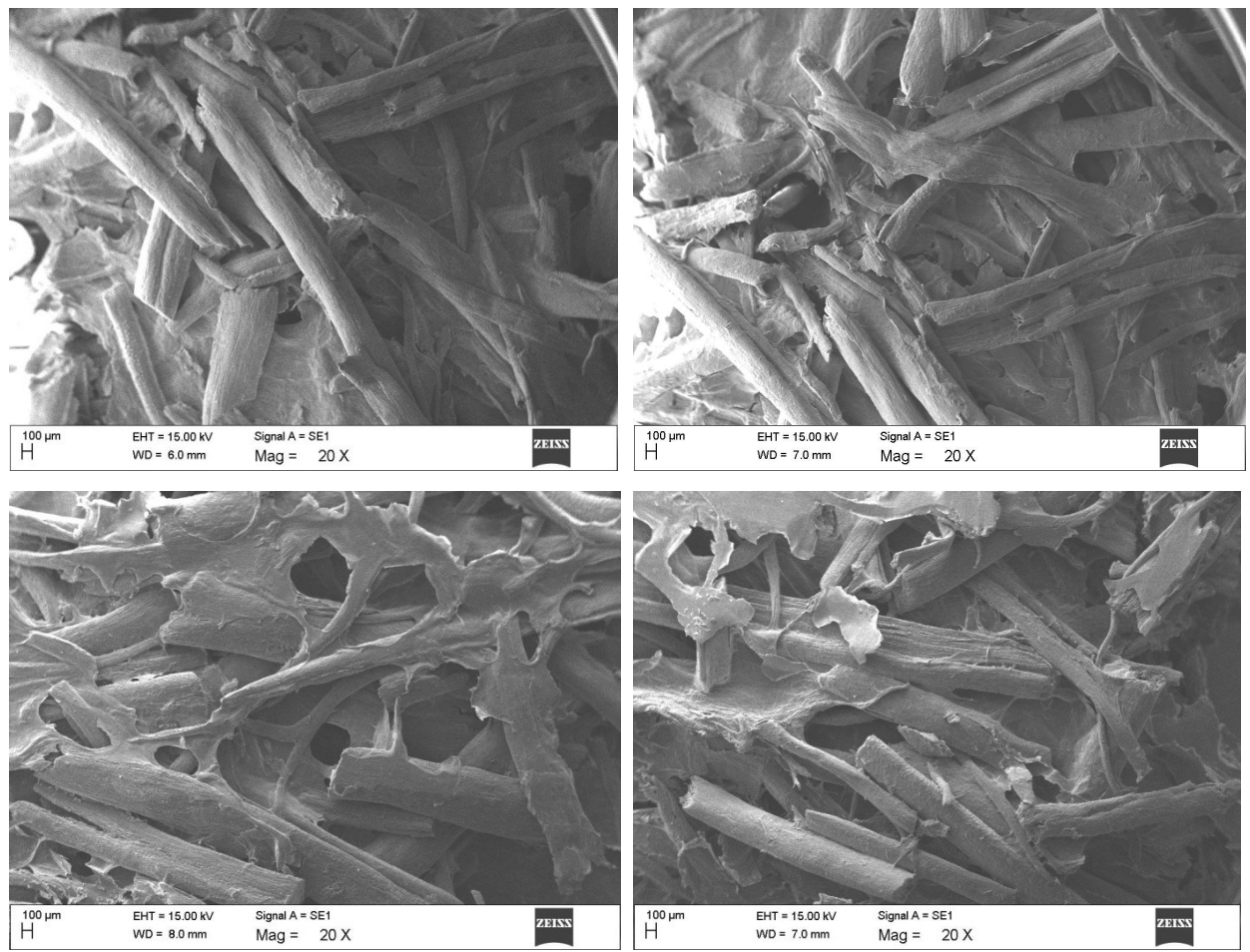

Figure 7: Comparison of SEM micrographs of non-treated (left) and alkaline-treated (right) of OPEFB fibre breakage part after water immersion (magnification at 20X).

\section{CONCLUSION}

OPEFB and seaweed composite exhibit desirable characteristics in terms of high water absorption performance particularly for non-treated composite. The alkaline treated composite obtained a higher thickness swelling percentage and sustained longer during water immersion, which was $18.23 \%( \pm 4.23)$ for $60 \mathrm{~min}$ of water immersion; whereas the non-treated composite showed lower thickness swelling percentage and slightly shorter immersion time, which was $7.78 \%( \pm 3.34)$ for 50 min of water immersion before composite degradation. This has clearly proved that a better surface interlocking towards the composite has been achieved by surface modification. Further study should be conducted in the future regarding the degradation period and mechanical strength of this composite before it can be applied as a soil stabiliser. 


\section{ACKNOWLEDGEMENTS}

The authors thank all parties which have been supporting this research work. The authors also would like to thank Universiti Sains Malaysia for financial support provided through Research University Grants 1001.PTEKIND.811343.

\section{REFERENCES}

1. Chiew, Y. L. \& Shimada, S. (2013). Current state and environmental impact assessment for utilizing oil palm empty fruit bunches for fuel, fiber and fertilizer - a case study of Malaysia. Biomass Bioenerg., 51, 109-124, https://doi.org/10.1016/j.biombioe.2013.01.012.

2. Hassan, M. M., Mueller, M. \& Wagners, M. H. (2008). Exploratory study on seaweed as novel filler in polypropylene composite. J. Appl. Polym. Sci., 109(2), 1242-1247, https://doi.org/10.1002/app.28287.

3. Alawar, A., Hamed, A. M. \& Al-Kaabi, K. (2009). Characterization of treated date palm tree fiber as composite reinforcement. Compos. B, 40(7), 601-606, https://doi.org/10.1016/j.compositesb.2009.04.018.

4. Jawaid, M. et al. (2010). Hybrid composites made from oil palm empty fruit bunches/jute fibres: water absorption, thickness swelling and density behaviours. J. Polym. Environ., 19(1), 106-109, https://doi.org/10.1007/ s10924-010-0203-2.

5. Ahmed, A. S. et al. (2010). Study of physical and mechanical properties of oil palm empty fruit bunch fiber reinforced polypropylene composites. $J$. Energy Environ., 2(1), 16-21.

6. Sreekala, M. S. \& Thomas, S. (2003). Effect of fibre surface modification on water-sorption characteristics of oil palm fibres. Compos. Sci. Technol., 63(6), 861-869, https://doi.org/10.1016/S0266-3538(02)00270-1.

7. Joseph, S. et al. (2010). Oil palm microcomposites: Processing and mechanical behavior. Polym. Eng. Sci., 50(9), 1853-1863, https://doi. org/10.1002/pen.21699.

8. Jacob, M., Thomas, S. \& Varughese, K. T. (2004). Mechanical properties of sisal/oil palm hybrid fiber reinforced natural rubber composites. Compos. Sci. Technol., 64(7-8), 955-965, https://doi.org/10.1016/S0266-3538(03)002616.

9. Luan, L. et al. (2010). Seaweed as novel biofiller in polypropylene composites. J. Appl. Polym. Sci., 118(2), 997-1005, https://doi.org/10.1002/ app.32462. 
10. Pandian, A. et al. (2014). Effect of moisture absorption behavior on mechanical properties of basalt fibre reinforced polymer matrix composites. J. Compos., Article ID 587980, https://doi.org/10.1155/2014/587980.

11. Rivai, M. et al. (2014). Characterization of oil palm empty fruit bunch and glass fibre reinforced recycled polypropylene hybrid composites. Fiber. Polym., 15(7), 1523-1530, https://doi.org/10.1007/s12221-014-1523-y.

12. Salman, S. D. et al. (2015). Physical, mechanical, and morphological properties of woven kenaf/ polymer composites produced using a vacuum infusion technique. Int. J. Polym. Sci., Article ID 894565, https://doi. org/10.1155/2015/894565.

13. Shen, C. \& Springer, G. S. (1976). Moisture absorption and desorption of composite materials. J. Compos. Mater., 10(1), 2-20, https://doi.org/10.117 7/002199837601000101.

14. Jayamani, E. et al. (2015). Dielectric properties of lignocellulosic fibers reinforced polymer composites: Effect of fiber loading and alkaline treatment. Mater. Today Proceed., 2, 2757-2766, https://doi.org/10.1016/j. matpr.2015.07.269.

15. Burey, P. etal.(2008). Hydrocolloid gel particles: Formation, characterization, and application. Crit. Rev. Food Sci. Nutr., 48(5), 361-377, https://doi. org/10.1080/10408390701347801.

16. Valadez-Gonzalez, A. et al. (1999). Effect of fiber surface treatment on the fiber-matrix bond strength of natural fiber reinforced composites. Compos. B, 30(3), 309-320, https://doi.org/10.1016/S1359-8368(98)00054-7.

17. Fernandes, E. M., Mano, J. F. \& Reis, R. L. (2013). Hybrid cork-polymer composites containing sisal fibre: Morphology effect of the fibre treatment on the mechanical properties and tensile failure prediction. Compos. Struct., 105, 153-162, https://doi.org/10.1016/j.compstruct.2013.05.012.

18. Orue, A. et al. (2015). The effect of surface modifications on sisal fiber properties and sisal/poly (lactic acid) interface adhesion. Compos. B, 73, 132-13812, https://doi.org/10.1016/j.compositesb.2014.12.022.

19. Costa, M. L., Almeida, S. F. M. \& Rezende, M. C. (2005). Hygrothermal effects on dynamic mechanical analysis and fracture behaviour of polymeric composites. Mat. Res., 8(3), 335-340, https://doi.org/10.1590/S151614392005000300019.

20. Abdul Khalil, H. P. S., Bhat, I.-u.-H. \& Sartika, M. Y. (2010). Degradation, mechano-physical, and morphological properties of empty fruit bunch reinforced polyester composites. Bioresour., 5(4), 2278-2296.

21. Karmaker, A. C. (1997). Effect of water absorption on dimensional stability and impact energy of jute fiber reinforced polypropylene. J. Mater. Sci. Lett., 16, 462-464, https://doi.org/10.1023/A:1018508209022. 
22. Muñoz, E. \& García-Manrique, J. A. (2015). Water absorption behaviour and its effect on the mechanical properties of flax fibre reinforced bioepoxy composites. Int. J. Polym. Sci., Article ID 390275, http://dx.doi. org/10.1155/2015/390275.

23. Ogah, A. O. et al. (2015). Water absorption, thickness swelling and rheological properties of agro fibers/HDPE composites. IOSR J. Polym. Text. Eng., 2(3), 66-73. 